NASA Technical Memorandum 102140

\title{
4 \\ Frequency Domain Model for Analysis of Paralleled, Series-Output-Connected Mapham Inverters
}

Andrew S. Brush

Sverdrup Technology, Inc.

NASA Lewis Research Center Group

Cleveland, Ohio

Richard C. Sundberg

General Dynamics Corporation

San Diego, California

and

Robert M. Button

National Aeronautics and Space Administration

Lewis Research Center

Cleveland, Ohio

Prepared for the

24th Intersociety Energy Conversion Engineering Conference cosponsored by the IEEE, AIAA, ANS, ASME, SAE, ACS, and AIChE Washington, D.C., August 6-11, 1989

\section{N/SA}

(NASA-TM-102140) FREQUENCY DOMAIN MODEL FOF 


\section{FREQUENCY DOMAIN MODEL FOR ANALYSIS OF PARALLELED, SERIES-OUTPUT-CONNECTED MAPHAM INVERTERS}

\author{
Andrew S. Brush ${ }^{1}$ \\ Sverdrup Technology, Inc. \\ NASA Lewis Research Center Group \\ Cleveland, $\mathrm{OH} 44135$
}

\author{
Richard C. Sundberg \\ General Dynamics Corporation \\ P.O. Box 85990 \\ San Diego, CA 92138
}

\author{
Robert M. Buttim \\ National Aeronautics and Spake Admuistration \\ Lewis Research Center \\ Cleveland, $\mathrm{OH} 44135$
}

\begin{abstract}
The Mapham resonant inverter is characterized as a twoport network driven by a selected periodic voltage. The two-port model is then used to model a pair of Mapham inverters connected in series and employing phasor voltage regulation. It is shown that the model is useful for predicting power output in paralleled inverter units, and for predicting harmonic current output of inverter pairs, using standard power flow techniques. Some examples are compared to data obtained from testing hardware inverters.
\end{abstract}

\section{INTRODUCTION}

Power systems operating at a bus frequency of $20 \mathrm{kHz}$ are currently under consideration for power distribution in spacecraft[1]. There are also potential applications in aircraft and other locations requiring compact electromechanical actuation systems[2]. Whatever the application, inverters will be required to convert DC source energy to $20 \mathrm{kHz}$. A leading inverter topology is the resonant circuit developed by Mapham[3], which offers high efficiency and low output distortion. In any such power system, multiple $20 \mathrm{kHz}$ drivers will be employed for reliability and flexibility. Where multiple $A C$ sources are connected in parallel to a system, the problem of regulating system voltage and power flow arises. A research program was undertaken at the NASA Lewis Research Center to characterize the performance of paralleled resonant inverters, to develop a model useful for control of inverters, and to increase our understanding of frequency domain analysis of resonant inverters.

The functional block to be modeled was the Main Inverter Unit (MIU), containing two Mapham inverters connected in series and employing phasor voltage regulation. The results of modelling an MIU were compared to data obtained from the PMAD/PV testbed at LeRC[4], which contains three $12 \mathrm{~kW}$ MIU's.

\footnotetext{
${ }^{1}$ Work supported by Contract NAS3-25266, Task Order 8801, "PMAD/PV Testbed Support."
}

\section{MODEL DEVELOPMENT}

Time domain simulations such as EASY5[5] have been very successful in modelling the operation of resonant power converters[6][7]. However, a large model containing two MIU's, a transmission line, and a load takes a large amount of computer CPU time to arrive at a steady state condition. In order to obtain a model which could be computed fast enough to be employed in on-line controllers, it was decided that a frequency-domain model would be employed.

In standard references on $A C$ utility power system analysis, such as Stevenson[8], a power source is typically modeled in the frequency domain as a voltage source in series with an impedance. This arrangement of source and impedance is similar to that described by Oruganti[9] as he proposed to model an inverter as a filtered voltage source. The advantages of taking the filter approach lie in the fact that it allows the use of standard load flow calculation techniques, and that the computations required to determine power transfer through the filter are simple. The issues to be resolved are selection of the proper filter parameters, and an appropriate input waveform.

\section{Filter}

The Mapham inverter power circuit to be modelled is shown in Fig. 1. This inverter is represented in the frequency domain by the equivalent circuit of Fig. 2. This is similar to models presented by Oruganti, and by Tsai and Lee[8], with the addition of the series capacitor and transformer reactances. Resistors have been inserted to model losses.

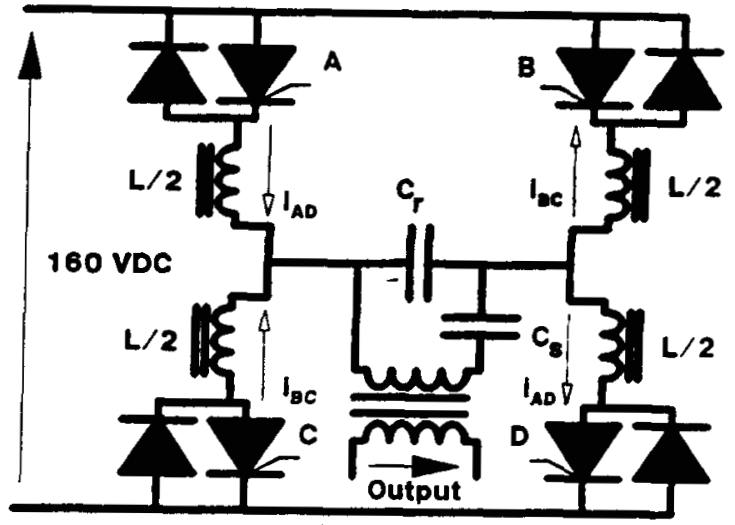

Figure 1 Mapham Inverter Circuit 


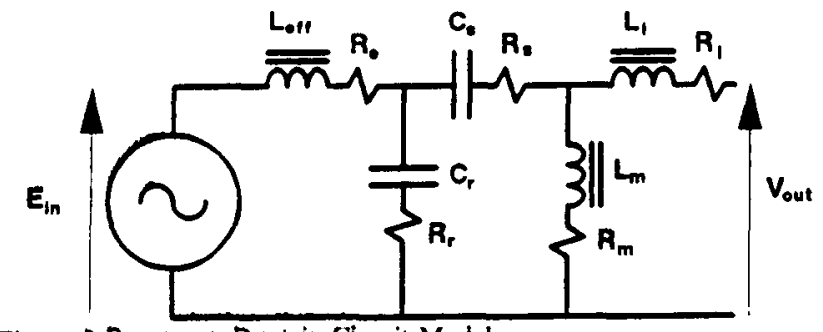

Figure 2 Frequtency Domain Circuit Model

The main new step taken in this model is the selection of the value to use for the resonant inductance. Oruganti used $\mathrm{L}$ in his model, while Tsai and Lee used $L / 2$ as an approximation. As observed by Sundberg, et. al.[10], neither of these values is accurate, since the effective resonant inductance of a Mapham inverter varies with the operating condition of the inverter. At no load, an accurate approximation of the effective resonant inductance $\mathrm{L}_{\text {eff }}$ can be determined by measuring the period $T_{\text {res }}$ of the inductor currents and noting that the resonant period is determined by the tank capacitor $C_{r}$ and the effective inductance:

$$
\begin{aligned}
& T_{\text {res }}=2 \pi \sqrt{L_{\text {eff }} C_{r}} \\
& L_{\text {eff }}=\frac{T_{\text {res }}^{2}}{4 \pi^{2} C_{r}}
\end{aligned}
$$

Unfortunately, when the inverter is loaded, the load becomes part of the resonant circuit, complicating the calculation of resonant period, and the above equations do not apply.

To understand the mechanism which determines $\mathrm{L}_{\mathrm{cff}}$, consider the inductor current waveforms of Fig. 3. During the time periods labelled M1, current flows in only one path between the DC supply terminals, through legs $A$ and $D$, or through legs $B$ and $C$. The series inductance of path $A D$ or $B C$ is equal to $L$. During the periods labeled $M 2$, all four inductors conduct, creating two parallel paths, both of inductance $\mathrm{L}$. In this mode, the resonant inductance is clearly $L / 2$. We propose to determine $\mathrm{L}_{\text {eff }}$ as an average of $\mathrm{L}$ and $\mathrm{L} / 2$, weighted by the proportion of the total $i^{2} t$

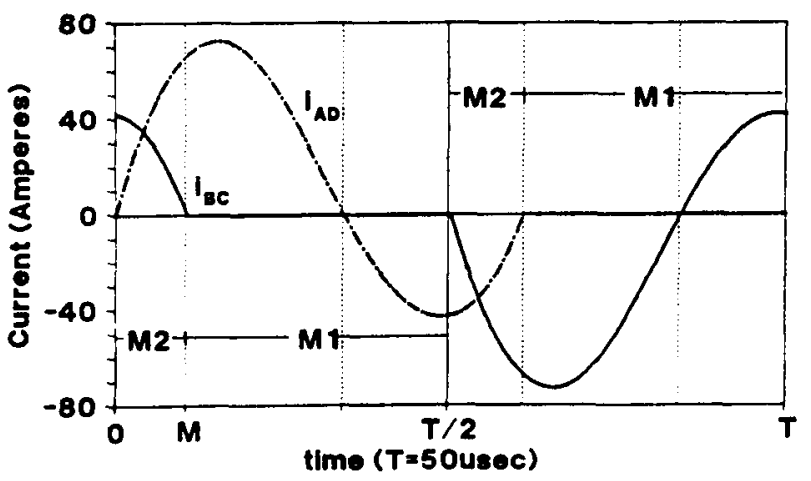

Figure 3 Inductor Currents flowing in each mode.

Consider a half period starting at the beginning of the mode $\mathrm{M} 2$ in at time 0 , transitioning into mode $\mathrm{M} 1$ in at time $M$, and continuing to time $T / 2$. The effective inductance will be found by:

$$
\begin{aligned}
& I_{M 2}=\int_{0}^{M} i_{A D}^{2}+i_{B C}^{2} d t \\
& I_{M 1}=\int_{M}^{T / 2} i_{A D}^{2} d t \\
& L_{e f f}=\frac{L}{2} \frac{I_{M 2}}{\left(I_{M 2}+I_{M 1}\right)}+L \frac{I_{M 1}}{\left(I_{M 2}+I_{M 1}\right)}
\end{aligned}
$$

$I_{M 2}$ is the total $i^{2} t$ flowing when all inductors are conducting, or when effective inductance is $\mathrm{L} / 2$. $\mathrm{I}_{\mathrm{M} 1}$ corresponds to an effective inductance of $\mathrm{L}$. Since each half period is symmetrical, there is no need to average over a full period.

Figure 4 shows a comparison between no load $L_{\text {eff }}$ calculated by the method of equations (1) and (2) with that found by (3), (4), and (5) at various switching frequencies, for the inverters in the testbed. It is seen that both methods arrive at a no load $L_{\text {eff }}$ of $0.86 \mathrm{~L}$ when the switching frequency is $20 \mathrm{kHz}$.

In order to determine values of $\mathrm{L}_{\text {eff }}$ to use in the model, inductor current data from EASY5 simulations of a testbed inverter was used to produce the map of $\mathrm{L}_{\text {eff }}$ vs. load given in Fig. 5. Assuming that inverter output voltage is $235 \mathrm{~V}$, data from the map is approximately fitted by the equation,

$$
L_{\text {eff }}=L_{1}+\left|I_{\text {out }}\right| \gamma \sin \phi
$$

where $\gamma=0.006$ for the testbed inverter, and $\phi$ is the angle by which inverter output voltage leads output current.

With all circuit values determined by analysis or measurement, the circuit of Fig. 2 is represented by the two-

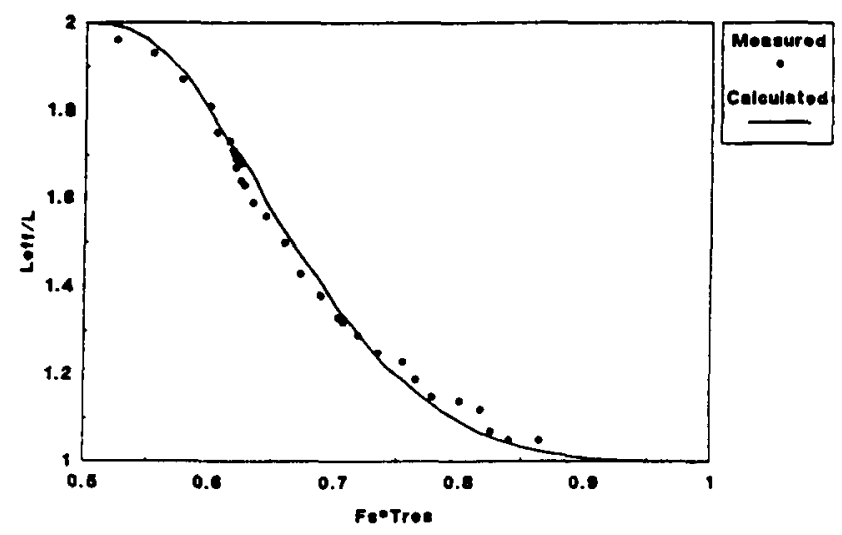

Figure 4 Effective Resonant Inductance vs. Normalized Switching Frequency 


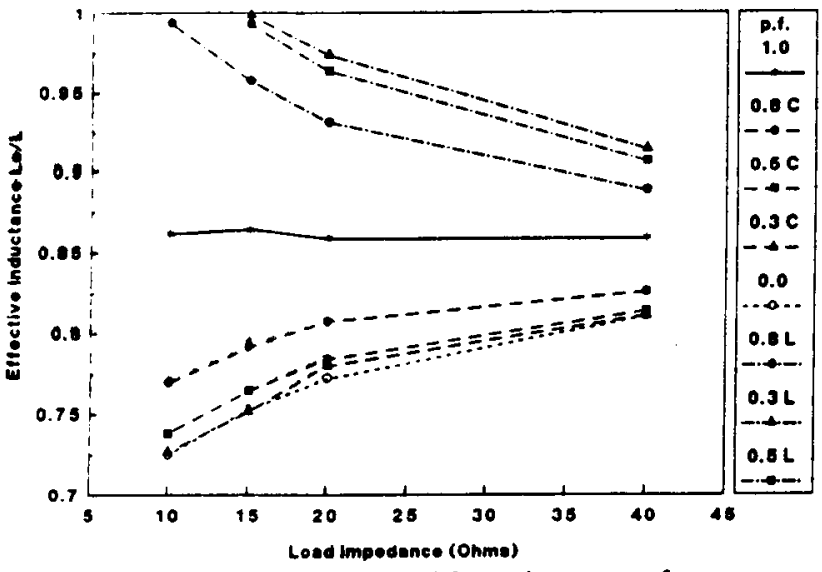

Figure 5 Resonant Inductance vs. Load for various power factors.

port of Fig. 6. Standard circuit analysis techniques are used to calculate the complex hybrid circuit parameters A, B, C, and D of the model two-port, such that:

$$
\begin{aligned}
& E_{\text {in }}=A V_{\text {out }}+B I_{\text {out }} \\
& I_{\text {in }}=C V_{\text {out }}+D I_{\text {out }}
\end{aligned}
$$

Of course, the parameters $A, B, C$, and $D$ are dependent on frequency, and need to be calculated for each harmonic.

\section{Driving Voltage}

Unlike the two-port parameters, which represent the actual characteristics of the inverter circuit, the input voltage $E_{\text {in }}$ is a made-up quantity which cannot be measured during inverter operation. Previous authors have suggested selecting a driving voltage based upon the operation of the inverter. Oruganti used the square wave of Fig. 7(a), which is suitable for analysis at the fundamental, but is a rough approximation at other harmonics. The wave of Fig. 7(b) was calculated by Tsai and Lee from simulation data, based upon a model with fixed $\mathrm{L}_{\text {eff }}$ of $\mathrm{L} / 2$, from the equation,

$$
e_{\text {in }}=L_{\text {eff }} \frac{d\left(i_{A D}-i_{B C}\right)}{d t}+v_{C}
$$

where $v_{c}$ is the voltage across the tank capacitor. Clearly, any change in the inverter operating condition will change the inductor currents, thereby changing the calculated $\mathrm{e}_{\text {in }}$. Also, as previously observed here, $\mathrm{L}_{\text {eff }}$ changes with operating condition.

It seems reasonable that a map of harmonic voltages and phase angles could be produced for all inverter loading

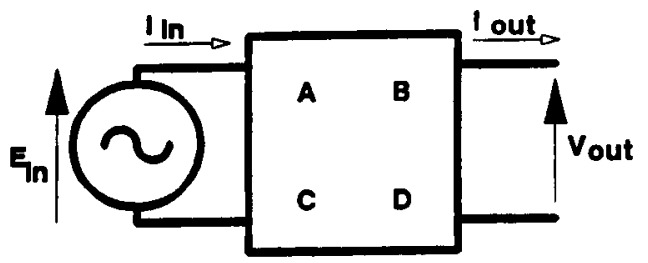

Figure 6 Two-port representation of a Mapham inverter.

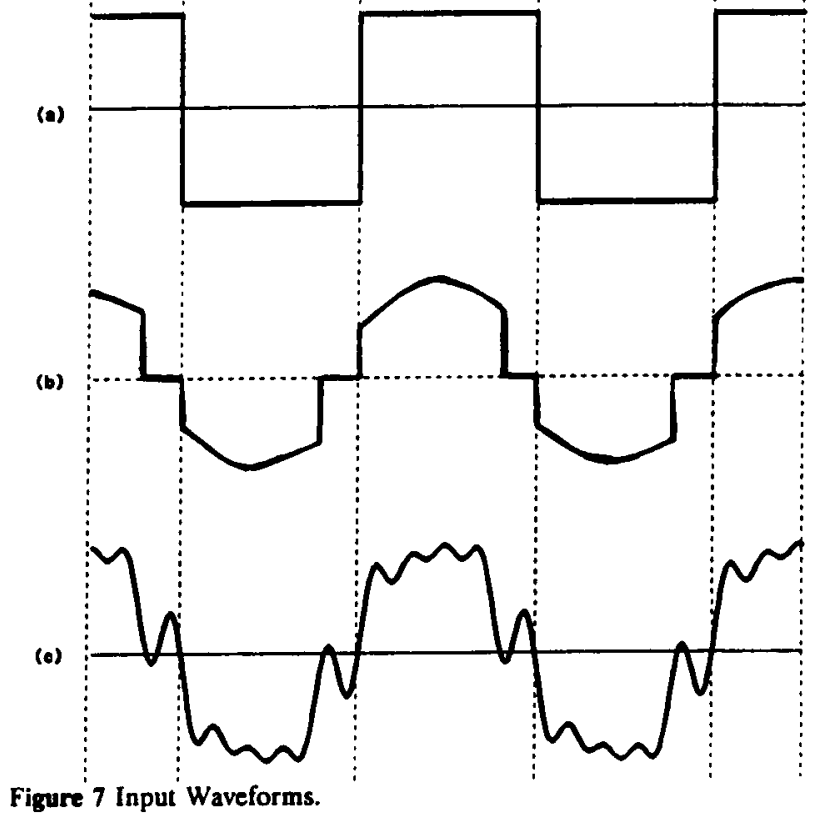

conditions using (7) and the simulation data used to produce Fig. 5. Although this was rejected for the present model in favor of an $E_{\text {in }}$ of fixed harmonic composition, we are proceeding to evaluate the advantages of such a map. The $E_{\text {in }}$ used in this model was calculated from actual measured open-circuit terminal voltage of an inverter in the testbed. For each harmonic considered, $E_{\text {in }}=A \hat{V}_{\text {out }} . \hat{V}_{\text {out }}$ is a vector determined from measurements of open circuit voltage made using a harmonic analyzing voltmeter. The $e_{i n}(t)$ wave used in this model (Fig. 7(c)) is the sum of the voltages at the fundamental, and harmonics $2,3,5,7$, and 9 .

It bas been observed that the output current of an inverter is linked to the phase relationship between the output voitage and the clock which times the firing of SCR's in the inverter. In this model, we tested the theory that the phase of the fundamental of $E_{i n}$ is analogous to the clock phase. While the phase of each harmonic in $E_{\text {in }}$ remains constant with respect to the fundamental, the fundamental is considered to be in phase with the inverter clock, which is variable in phase. This is not an exact assumption, but was deemed adequate for a simple model.

\section{Assembly of MIU model}

The testbed MIU's consist of two complete inverters such as that in Fig. 1 connected with the transformer outputs in series. To model a MIU, two two-port networks representing the circuit of Fig. 2 are connected as shown in Fig. 8. The transformer connections impose the constraint that the output current of each inverter is identical to the MIU output current. When the two-port equations are combined with this constraint, MIU output current is given by:

$$
I_{\text {MIU }}=\frac{E_{1} A_{2}+E_{2} A_{1}-A_{1} A_{2} V_{\text {line }}}{A_{1} B_{2}+A_{2} B_{1}}
$$




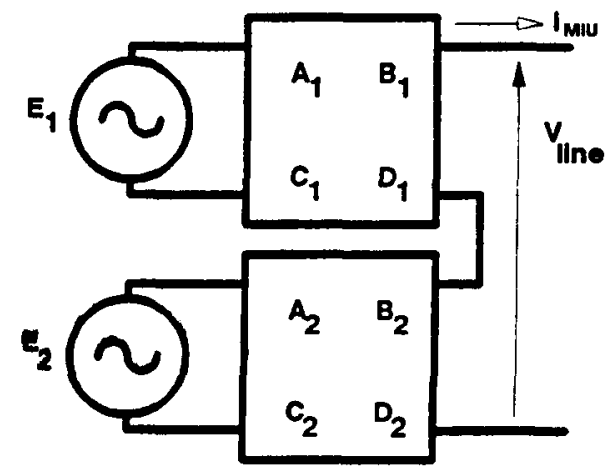

Figure 8 Model of Complete MIU.

For given conditions of line voltage $V_{\text {line }}$ and clock phases (which determine the phase of $E_{1}$ and $E_{2}$ ), the corresponding $\mathrm{I}_{\mathrm{mu}}$ must be found iteratively. This is due to the fact that the inverter operating conditions, and thence the $A B C D$ parameters, are determined by the inverter output. A computer subroutine has been written which performs all the required calculations to find MIU output current at the fundamental, and at harmonics $2,3,5,7$, and 9. This subroutine has been used in a loadflow of the simple system shown in Fig. 9. The loadflow used standard linear iterative methods to identify the line voltage and angle which would achieve conservation of real and reactive power. The following section compares results from the loadflow to data obtained from the testbed.

\section{RESULTS}

The loadflow of Fig. 9 was run using input data corresponding to actual testbed runs for which data was available. The usefulness of this model in predicting power output and harmonic current flow was checked against the hardware data. In the following discussion of results, the term "clock phase" will be used to refer to the phase angle of the clock of inverters \#1\#3, and to the phase of the fundamental of $E_{1}$ and $E_{3}$ in the model. "Regulation angle" will refer to the angle by which the clocks of the inverters \#2 and \#4 lag inverters \#1 and \#3, respectively, and to the angle by which the fundamental of $E_{2}$ and $E_{4}$ lag $E_{1}$ and $E_{3}$, respectively (Fig. 10).

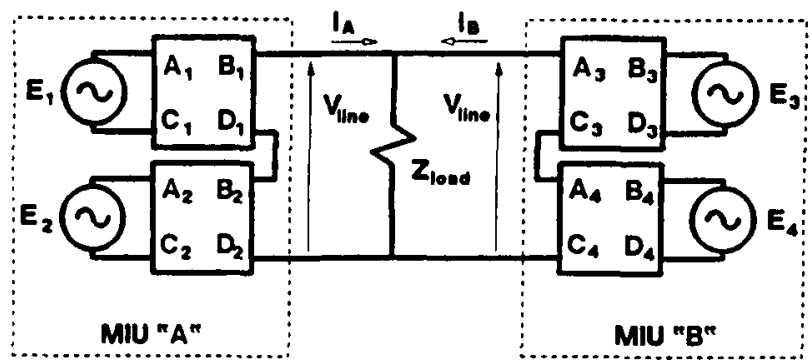

Flgure 9 System Model.

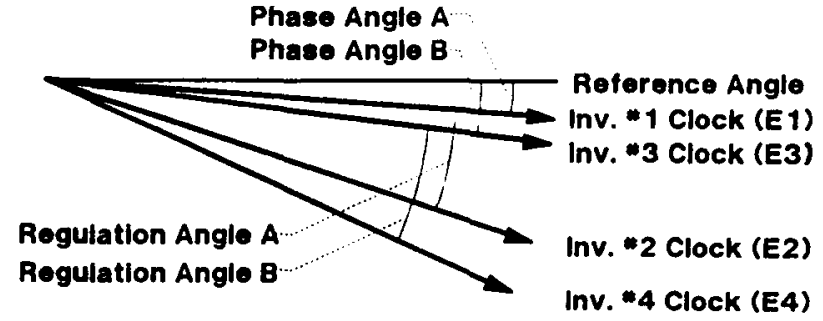

Figure 10 Phasor Relationship between inverter clocks.

\section{Power Sharing - Phase Control}

In this test, the regulation angle of each MIU was maintained at zero, while the difference between the clock phases of MIU "A" and "B" was varied. The results are presented in Figure 11. These plots show that the model has qualitative agreement with hardware data. The model is more sensitive to changes in phase angle than the hardware. Also, the PMAD/PV MIU's attained exact power division at a relative phase angle slightly off from the expected zero. This is no doubt due to differences in the actual component values between MIU's, and differences in propagation delays in the firing and logic circuits of the MIU's.
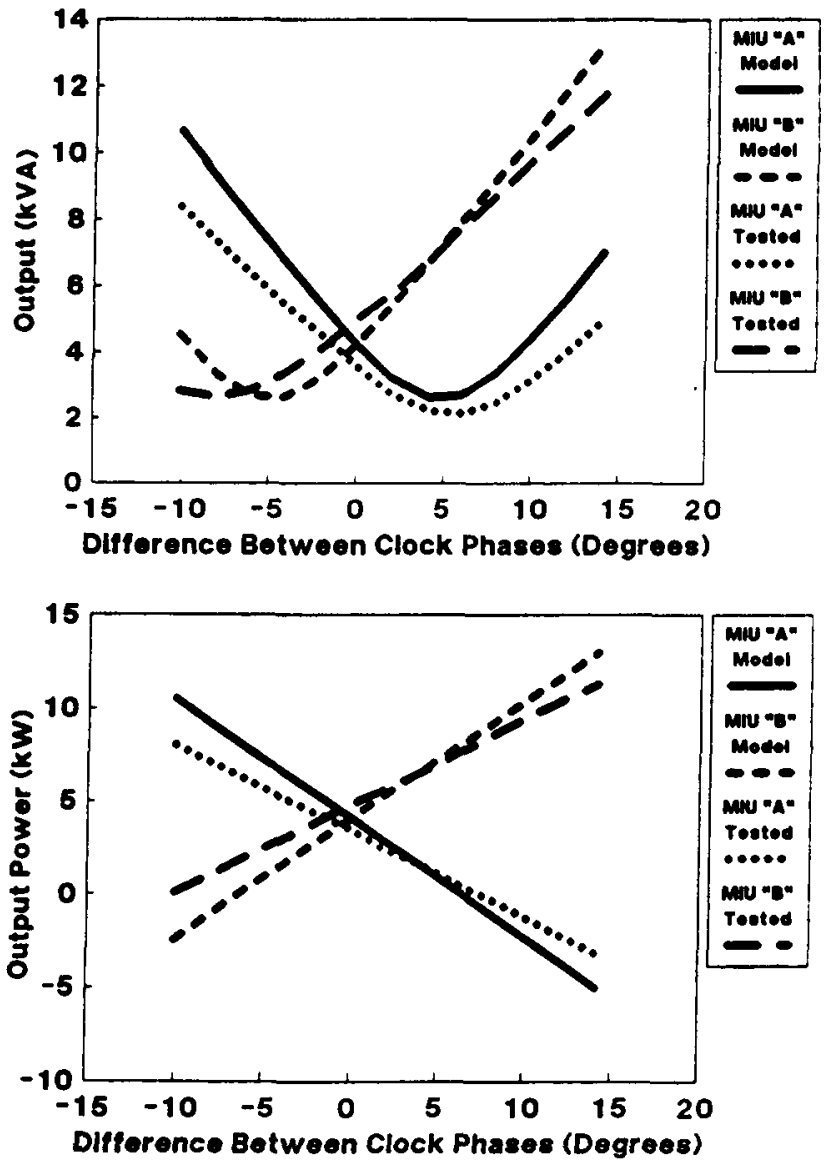

Figure 11 MIU Output vs. Clock Phase Difference 


\section{Power Sharing - Regulation Angle Control}

This test was accomplished by leaving the clock phase of both MIU's at zero, and varying the regulation angle of each inverter. Figure 12 shows that, as in the phase control test, the PMAD/PV MIU's achieve even power division at an offset from zero, probably due to the same causes. At lower power outputs, the model corresponds reasonably well with the breadboard data, with the exception that, again, the model is more sensitive to changes in angle. At higher power output, the model diverges from the test data.

In the breadboard tests, and in the loadflow, differences in regulation angle in excess of fourteen degrees were achieved by setting MIU "A" to maximum voltage output (zero regulation angle), and increasing the regulation of MIU " $\mathrm{B}$ " to the desired point. Above this point, MIU "B" is supplying inductive VAR, and is exceeding its current rating. In this case, the assumption that $E$ remains fixed in phase with respect to the inverter clock seems to break down badly.

\section{Harmonic Loadflow}

Figure 13 shows the output of the original loadflow model when operating at a phase angle of five degrees, and no regulation. Note that the fifth harmonic current is significant, although the line voltage remains undistorted. The oscilloscope photograph of Fig. 14, taken under similar
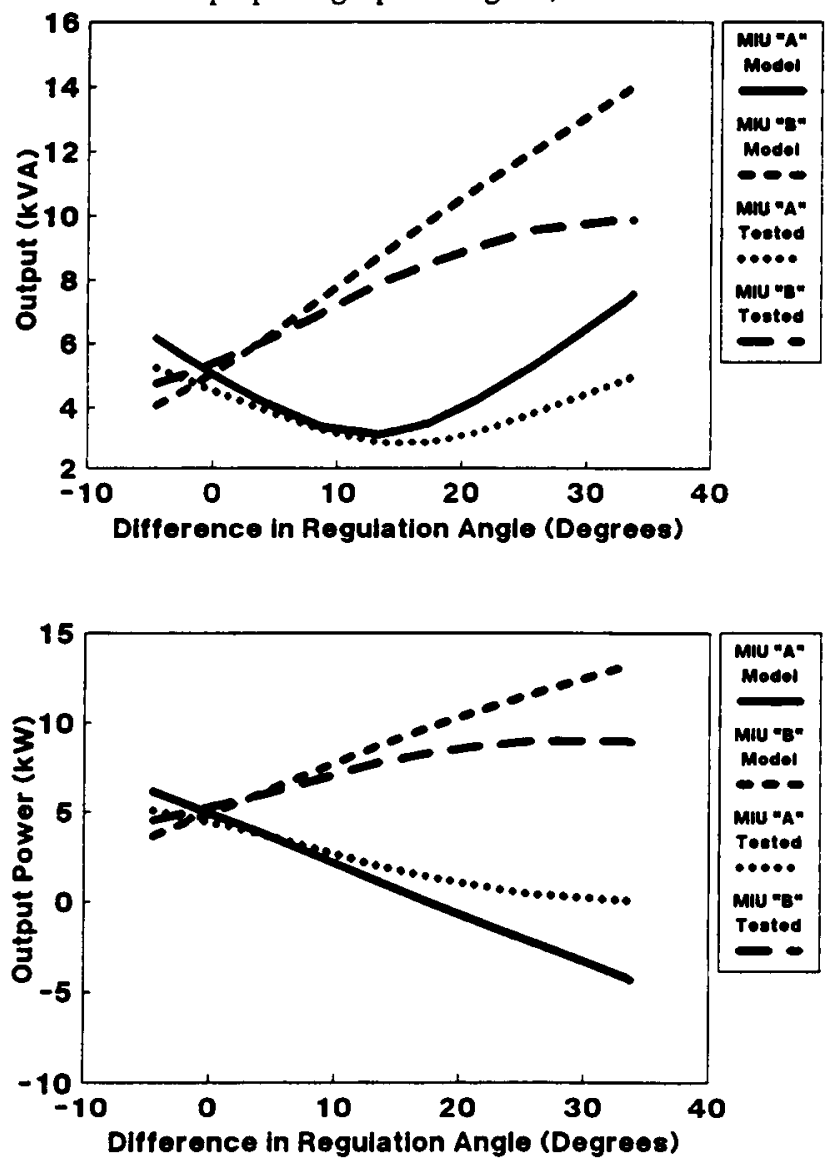

Figure 12 MIU Output vs. Regulation Angle Difference.

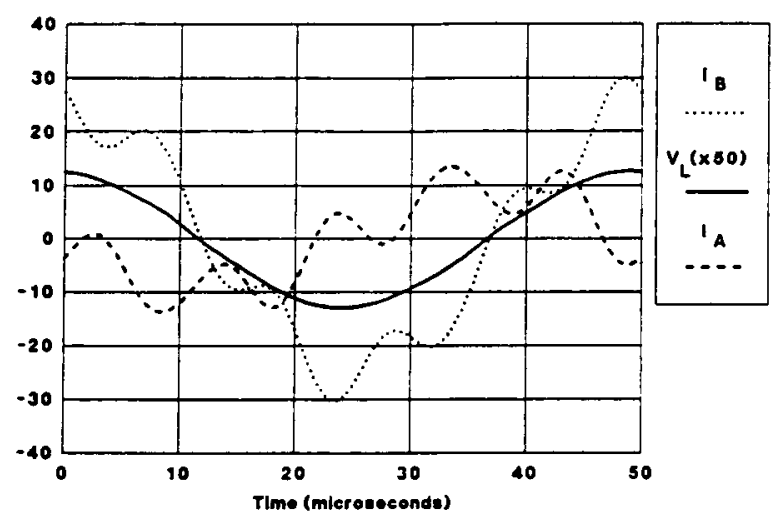

Figure 13 Unfiltered MIU Output Calculated by Harmonic Loadflow

conditions, reveals that the prediction of fifth harmonic circulating currents is accurate.

Since it is preferable to eliminate circulating harmonic currents, some testing was conducted in the testbed to

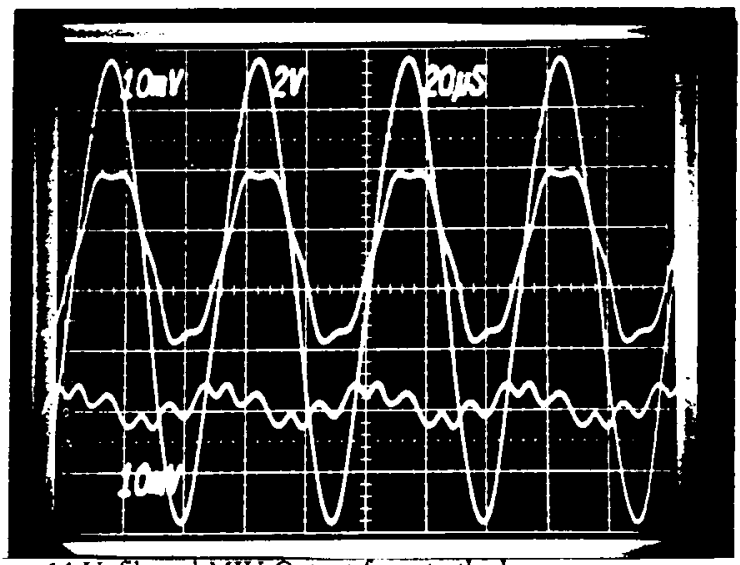

Figure 14 Unfiltered MIU Output from testbed.

evaluate the efficacy of applying series-resonant LC filters to the inverter output. Fig. 15 shows the result given by the loadflow when a filter composed of a $2 \mu \mathrm{F}$ capacitor in series with a $31 \mu \mathrm{H}$ inductor, with a $10 \mathrm{Ohm}$ resistor shunting the LC combination, is applied to each MIU output. Clearly, the filter reduced the harmonic currents.

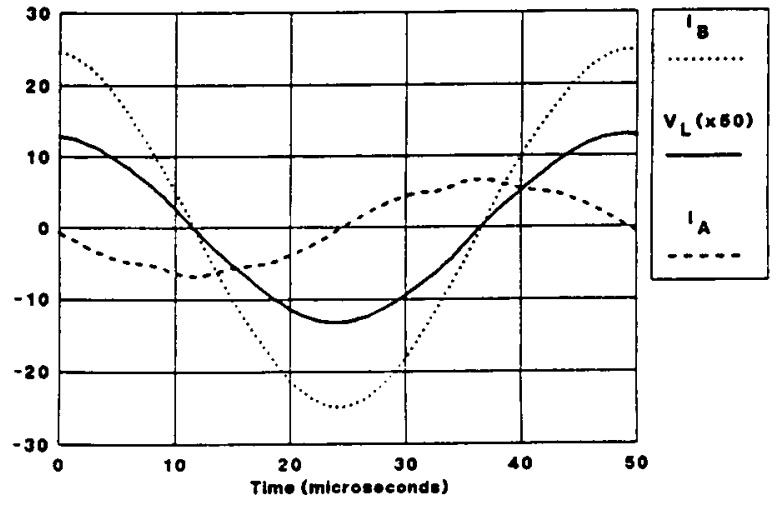

Figure 15 Filtered MIU Output Calculated by Harmonic Loadflow 


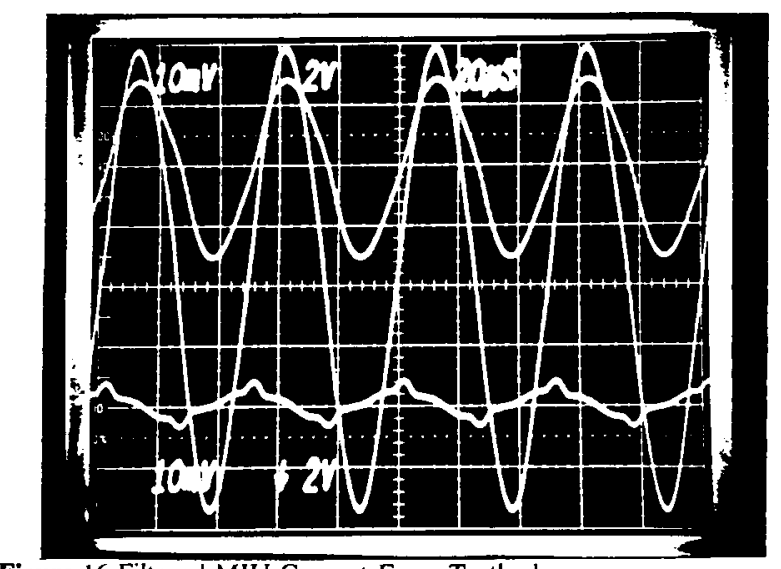

Figure 16 Filtered MIU Current From Testbed.

Fig. 16 gives the MIU outputs given by the testbed with the same filters. The model results are very similar to the actual measured data, despite the fact that losses in the filter were not modeled.

Note that the operating condition used for this test, with one MIU supplying no power, is unrealistic, and was selected for demonstration purposes only. In more normal conditions, with inverters evenly dividing power output, circulating harmonics are minimal without filters.

\section{MODEL PERFORMANCE}

In the comparisons discussed above, the model gave acceptable qualitative results. The model accurately represented trends in inverter output with respect to the inverter clock signals, although overestimating the sensitivity of the system to changes in clock phase angles. A good forecast of circulating harmonic current was obtained, and the performance of a model filter is comparable to that of a real filter.

The deficiencies in quantitative performance may stem from oversimplification in selection of the model input voltage $\mathrm{E}$. It is obvious that the input voltage of equation (9) will vary in harmonic content as the resonant period changes with load. Not so evident is that the input voltage $E$ seems to vary in phase with respect to the actual inverter clock as the resonant period varies with load. Further investigations using hardware data in conjunction with EASY5 time domain simulations are underway, and should increase understanding of how to model the voltage $\mathrm{E}$.

\section{CONCLUSIONS}

The frequency domain model of MIU's operating in parallel verified the idea that impedance-based techniques for analysis of real and reactive power transfer can be applied to resonant inverters.

The circuit analysis and loadflow techniques found in any introductory text on power system analysis are applicable to high frequency systems employing resonant inverters.
In a frequency domain model of a Mapham inverter, the phase of the model input voltage $E_{\text {in }}$ is approximately analogous to the phase of the inverter clock.

The impedance model gave reasonable performance at harmonics of the fundamental switching frequency, and should be useful as a tool for filter design.

The method of calculating the effective resonant inductance $\mathrm{L}_{\text {eff }}$ gives better results in frequency domain analysis than either $L$ or $L / 2$ used previously.

\section{REFERENCES}

[1] General Dynamics Space Systems Division, "Resonant AC Power System: Proof of Concept Test Program," Final Report, Vol. 1, NASA CR175069, October, 1986.

[2] A.C. Hoffman, et. al.,"Advanced Secondary Power System for Transport Aircraft," NASA TP2463, May, 1985

[3] N. Mapham, "An SCR Inverter with Good Regulation and Sine-Wave Output," IEEE Transactions on Industrial General Applications, Vol. IGA-3 Mar./Apr. 1967, pp.176187.

[4] J. Mildice and R. Sundberg, "AC Power System Testbed," Final Report, NASA CR175068, Nov., 1987

[5] Boeing Computer Services Company, "EASY5 Dynamic Analysis System User's Guide," April, 1983.

[6] R. Sundberg, A. Brush, A. Patterson, R. Button, "Distortion and Regulation Characterization of a Mapham Inverter," 24th. Intersociety Energy Conversion Engineering Conference, Aug. 6-11, 1989

[7] F-S Tsai and F.C. Lee, "Effects of Load on the Performance of the Mapham Resonant Inverter," IECEC Conference Record, August, 1988, pp.245-251.

[8] W.D. Stevenson, "Elements of Power System Analysis," $4^{\text {th }}$ Ed., McGraw-Hill, New York, 1982.

[9] R. Oruganti, "A Filter Approach to the AC Bus Systems," EE6400 Project Report, Electrical Engineering Department, VPI\&SU, Blacksburg, VA, June, 1985.

[10] R. Sundberg, A. Brush, and A. Patterson, "Main Inverter Unit Distortion Test Report," NASA LeRC Space Station Systems Directorate PIR \#220, November 2, 1988

\author{
ORIGINAL PAGE \\ BLACK AND WHITE PHOTOGRAPH
}




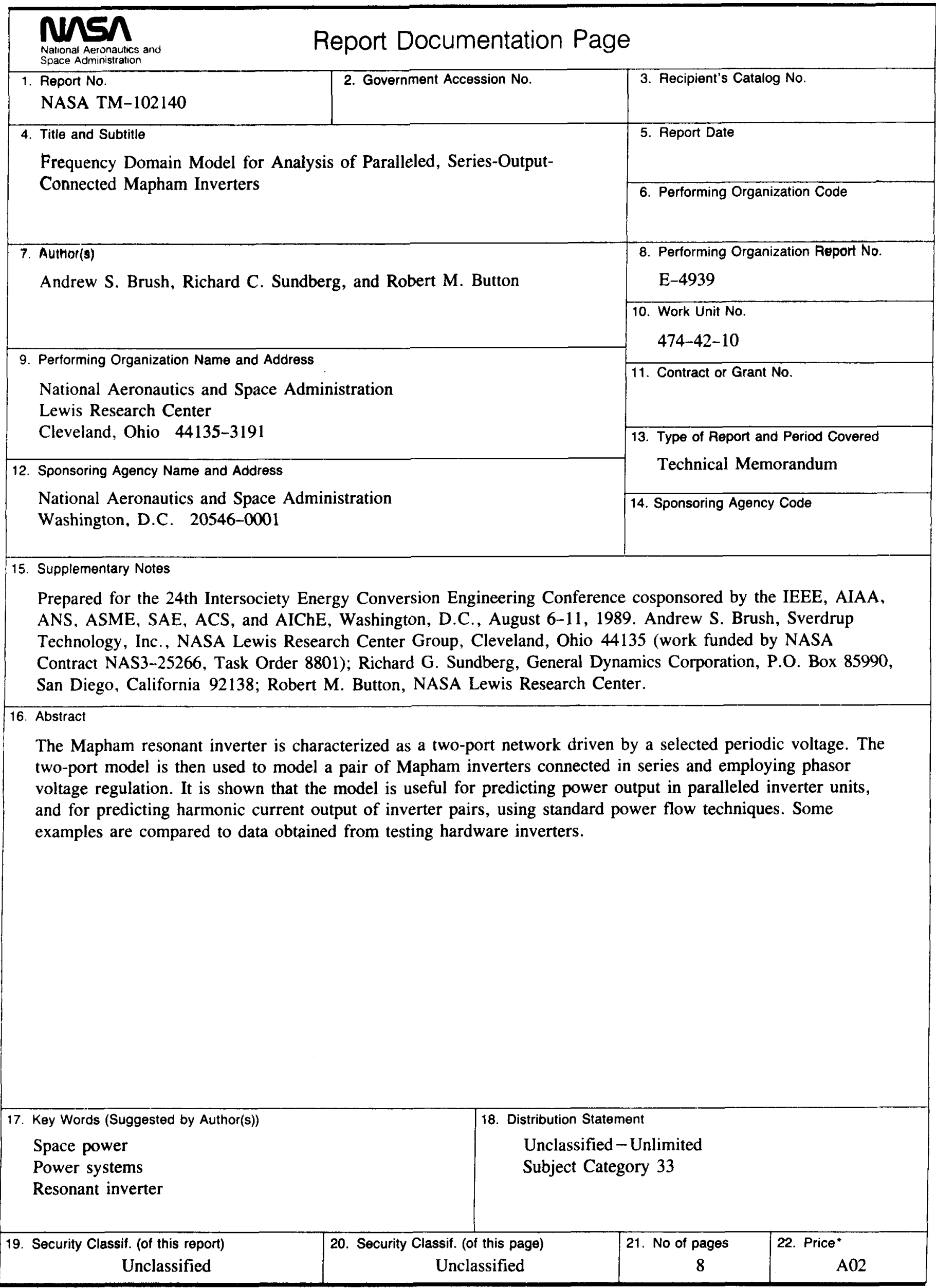

